Article

\title{
Effects of SC-560 in Combination with Cisplatin or Taxol on Angiogenesis in Human Ovarian Cancer Xenografts
}

\author{
Wei Li *, Liang Wan, Ling-Yun Zhai and Jane Wang \\ Department of Gynecology, Nanjing Medical University of Hangzhou Hospital, \\ 261 Huansha Road, Hangzhou 310006, China; E-Mails: wanliang20069@126.com (L.W.); \\ ZIyinhz@hotmail.com (L.-Y.Z.); wangjingjane@hotmail.com (J.W.) \\ * Author to whom correspondence should be addressed; E-Mail: wei5901482@hotmail.com; \\ Tel.: +86-571-5600-5600; Fax: +86-571-8791-4773.
}

External Editor: Bing Yan

Received: 17 August 2014; in revised form: 10 October 2014 / Accepted: 16 October 2014 / Published: 23 October 2014

\begin{abstract}
This study was designed to evaluate the effect of cyclooxygenase-1 (COX-1) inhibitor, SC-560, combined with cisplatin or taxol, on angiogenesis in human ovarian cancer xenografts. Mice were treated with intraperitoneal (i.p.) injections of SC-560 $6 \mathrm{mg} / \mathrm{kg} /$ day, i.p. injections of cisplatin $3 \mathrm{mg} / \mathrm{kg}$ every other day and i.p. injections of taxol $20 \mathrm{mg} / \mathrm{kg}$ once a week for 21 days. Vascular endothelial growth factor (VEGF) mRNA levels were detected by reverse transcription-polymerase chain reaction (RT-PCR); microvessel density (MVD) was determined by immunohistochemistry; and prostaglandin $\mathrm{E}_{2}$ $\left(\mathrm{PGE}_{2}\right)$ levels were determined using ELISA. Expression levels of VEGF mRNA and MVD in treatment groups were inhibited significantly when compared with the control group ( $p<0.05$ for all), and SC-560 combined with cisplatin displayed a greater reduction in the expression of VEGF and MVD than SC-560 or cisplatin alone $(p<0.05)$. SC-560 combined with taxol showed a greater inhibition on VEGF mRNA expression than SC-560 or taxol alone $(p<0.05)$. The level of $\mathrm{PGE}_{2}$ in treatment groups was significantly reduced when compared with the control group ( $p<0.01$ for all). These findings may indicate that cisplatin or taxol supplemented by SC-560 in human ovarian cancer xenografts enhances the inhibition effect of cisplatin or taxol alone on angiogenesis.
\end{abstract}


Keywords: ovarian cancer; SC-560; cisplatin; taxol; angiogenesis

\section{Introduction}

Ovarian cancer is a common malignancy responsible for more deaths worldwide than any other malignancy of the female reproductive system [1]. Ovarian cancer growth is angiogenesis dependent and increased production of angiogenic growth factors such as vascular endothelial growth factor (VEGF) correlates with clinical stage, therapy efficacy, tumor metastasis and patient survival in human ovarian carcinoma [2]. At present, surgery, platinum and paclitaxel-based chemotherapy are still the main treatment methods for ovarian cancer [3]. Although $75 \%-80 \%$ of ovarian cancer patients can respond to chemotherapy at the initial stage, more than $80 \%$ of the patients that underwent chemotherapy may display drug resistance, even multi-drug resistance (MDR), ultimately, leading to the five year survival rate of only $30 \%$, suggesting MDR is a common cause of the failure of chemotherapy in ovarian cancer [4]. Cisplatin is a platinum compound that was discovered in the 1960s and has been an important chemotherapeutic drug for the treatment of many cancers, including ovarian ones, as a single agent or in combination with other anticancer agents [5-7]. Taxol belongs to a family of microtubule-targeting drugs called the taxanes [8], which work by promoting assembly and stabilization of microtubules, thus preventing depolymerization. Taxanes are widely used to treat patients with lung, breast, stomach, endometrium or ovarian cancers [9]. The tolerance to taxol and cisplatin in ovarian cancer cells has been observed [10]; however the mechanisms of their resistance are not yet fully understood.

Cyclooxygenase (COX) is a key rate-limiting enzyme that catalyzes the biotransformation of arachidonic acid into prostaglandins and thromboxane, which mediate a range of physiological and pathophysiological responses [11]. The constitutively expressed isoform COX-1 is responsible for maintaining homeostasis and normal production of eicosanoids, whereas the inducible isoform COX-2 is implicated in the synthesis of prostanoids involved in acute and chronic inflammatory processes [12]. Studies have demonstrated that COX-2 up-regulates in a range of malignant neoplasms while the contribution of COX-1 remains undefined or controversial [13]. Dore et al. first documented that the epithelium covering the surface of the ovary, from which ovarian adenocarcinomas are believed to be derived, expressed abundant amounts of COX-1 [14]. A growing body of research focused on the up-regulation of COX-1 in many malignant tumors [15,16], especially in ovarian cancer as well as cell lines [17-19]. Moreover studies have demonstrated that COX-1 is over-expressed in various stages (onset and progression) of human epithelial ovarian cancers, where it controls the production of prostaglandins and promotes angiogenic growth factor production $[13,17,19]$. On the basis of these studies, it is concluded that COX-1 may contribute to carcinoma development in the ovary through stimulation of neovascularization. As a consequence, COX-1 might be an ideal target for theranostic investigations of human epithelial ovarian cancers [13]. 
Non-steroidal anti-inflammatory drugs (NSAIDs) are known to be inhibitors of the COXs and thus impede cancer growth primarily through blocking arachidonic acid metabolism by attenuating COX activity and reducing levels of prostaglandins. Ferrandina et al. found that COX-2 over-expression was associated with chemotherapy resistance [20], and its over-expression might reduce the efficacy of taxol [21]. In recent years, studies have reported the inhibitory effects of COX-2 inhibitors in combination with taxol on tumor growth [22,23]. Based on these studies, the combination of COX-2 selective inhibitor and taxol has already been used in phase II trials of some solid tumor treatment [24-26]. Numerous studies have shown that COX-1 is involved in the progression of ovarian carcinoma and that COX-1 selective inhibitors may inhibit tumor growth by inhibiting tumor angiogenesis $[2,13,17,19,27]$. However, studies of COX-1 inhibitors in combination with cisplatin or taxane on angiogenesis in human ovarian cancer xenografts have been rarely documented. In this study, using mice transplanted with a human ovarian cancer SKOV-3 cell lines as an experimental model system, we investigate the effects of SC-560, a selective COX-1 inhibitor, in combination with cisplatin or taxol on ovarian tumor growth and angiogenesis in a human ovarian cancer xenograft.

\section{Results and Discussion}

\subsection{Inhibition of Ovarian Cancer Growth}

When the tumors became visible ( 7 days after inoculation), mice were randomly separated into six groups (six mice in each group). SC-560 was administered by oral gavage at a dose of $3 \mathrm{mg} / \mathrm{kg}$ twice a day. Taxol was given by intraperitoneal (i.p.) injection at a dose of $20 \mathrm{mg} / \mathrm{kg}$ once a week. Cisplatin was administered by i.p. injection at a dose of $3 \mathrm{mg} / \mathrm{kg}$ every other day. Figure 1 shows the relative effect of SC-560 in combination with cisplatin or taxol on tumor growth. We observed that the tumor size increased throughout the period examined in the control group since the date of injection, whereas the average tumor size in all the drug-treated mice were significantly suppressed. For instance, on day 28, the mean tumor volume in control mice was $719 \mathrm{~mm}^{3}$. Under similar conditions, the mean tumor volume of the SC-560-treated group was $349 \mathrm{~mm}^{3}$ and cisplatin-treated group animals showed a mean tumor volume of $418 \mathrm{~mm}^{3}$. SC-560 was found to inhibit ovarian cancer growth better when compared with cisplatin in the experiment. And tumor growth was significantly reduced during the entire treatment period with SC-560. On day 28, the tumor size of mice in the SC-560, taxol and SC-560/taxol combination group was reduced by $44.67 \%, 54.48 \%$ and $55.35 \%$, respectively, compared with the control mice. Moreover, the inhibitory effect observed in the SC-560, cisplatin, taxol and combination groups was all statistically significant compared with that of the control group $(p<0.05$ for all). 
Figure 1. Effects of SC-560 combined with cisplatin or taxol on tumor growth in vivo. After 7 days had elapsed to allow for tumor establishment, mice were randomly separated into six groups (six mice in each group). Mice were treated with SC-560 (3 mg/kg twice a day), cisplatin ( $3 \mathrm{mg} / \mathrm{kg}$ every other day) and taxol (20 mg/kg once a week) for 21 days. Average tumor volume of mice in all treatment groups was significantly different from control mice on day $28 .{ }^{*} p<0.05$, compared with control.

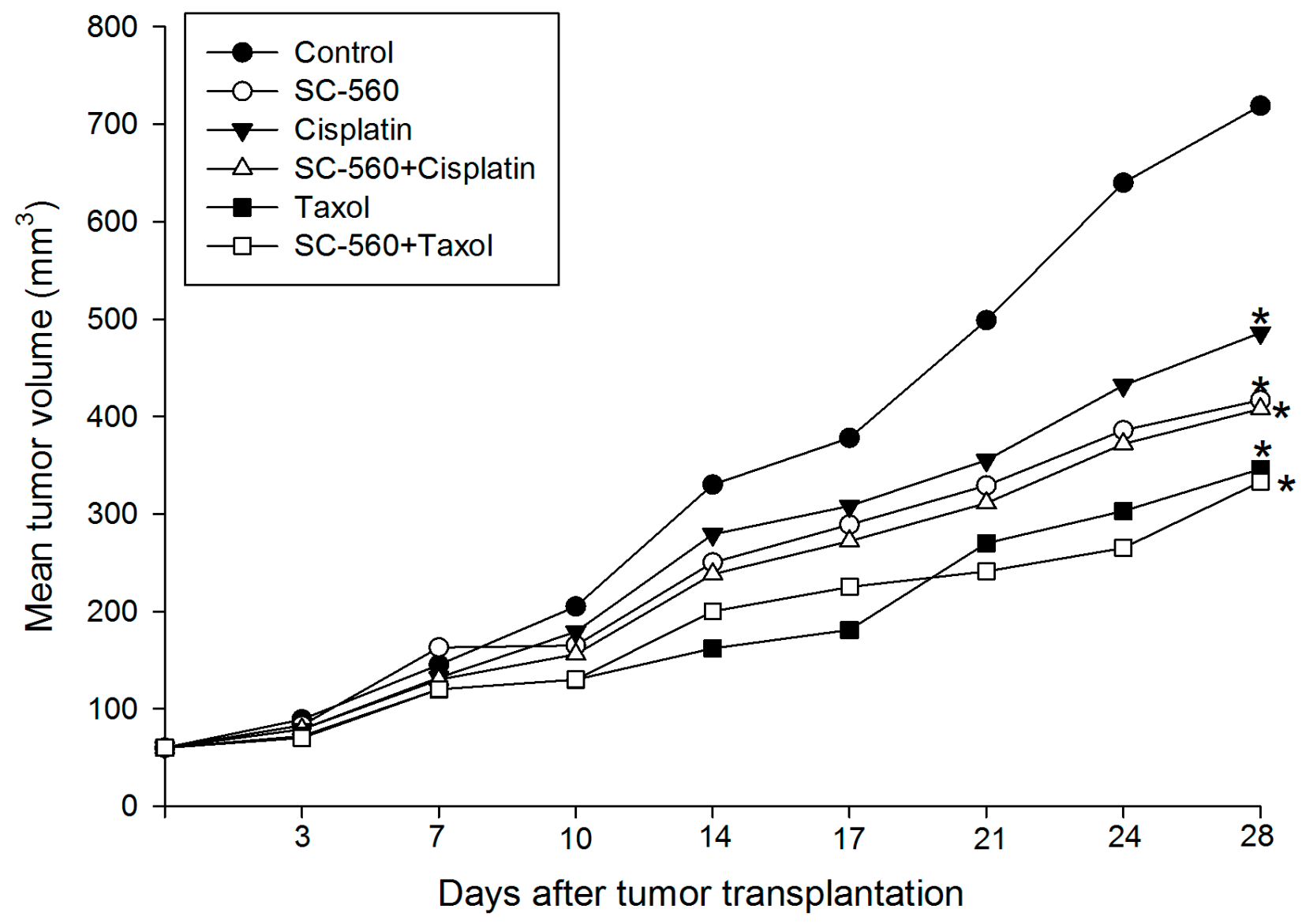

\subsection{Effect on Microvessel Density (MVD)}

Immunohistochemical analysis of frozen tumor sections show a decrease in the number of CD34 positive microvessels in mice treated with SC-560, cisplatin, SC-560/cisplatin, taxol and SC-560/taxol (Figure 2). MVD in the treatment groups was $40.50 \pm 8.92$ (SC-560), $48.53 \pm 10.37$ (cisplatin), $30.30 \pm 6.41$ (SC-560/cisplatin), $53.43 \pm 5.56$ (taxol) and $48.20 \pm 4.05$ (SC-560/taxol), which was statistically significant compared with that of the control group $(73.77 \pm 6.94)(p<0.05$ for all). Sections from tumors grown in mice treated with SC-560 combined with cisplatin displayed a greater reduction in MVD compared with SC-560-treated group and cisplatin-treated group $(p<0.05)$. And SC-560 combined with taxol decrease the number of MVD to a greater extent when compared with the taxol-treated group $(p<0.05)$. Representative pictures of CD34 immunohistochemical staining of tumors show the effects of SC-560 on MVD in SKOV-3 xenograft tumors (Figure 3). 
Figure 2. Effects of SC-560 combined with cisplatin or taxol on microvessel density (MVD) in vivo. MVD of control group compared with drug-treated groups illustrated the significantly inhibitory effect of SC-560 in combination with cisplatin or taxol on tumor. * MVD of treatment groups compared with control group, $p<0.05$ for all; * $p<0.05$; error bars indicate standard error.

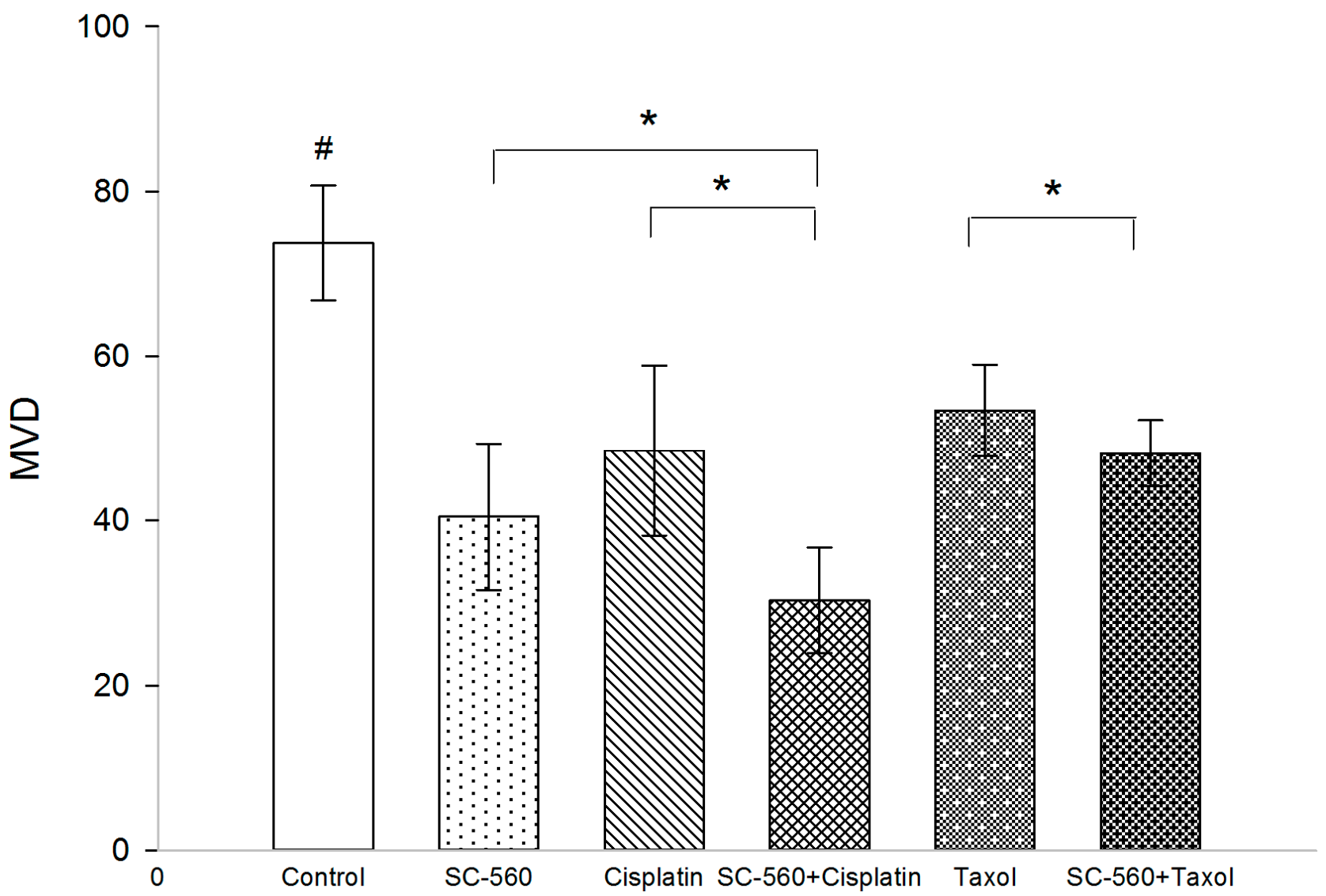

Figure 3. Effects of SC-560 on angiogenesis in SKOV-3 xenograft tumors. Representative pictures of CD34 immunohistochemical staining of tumors. Magnification is $100 \times$.

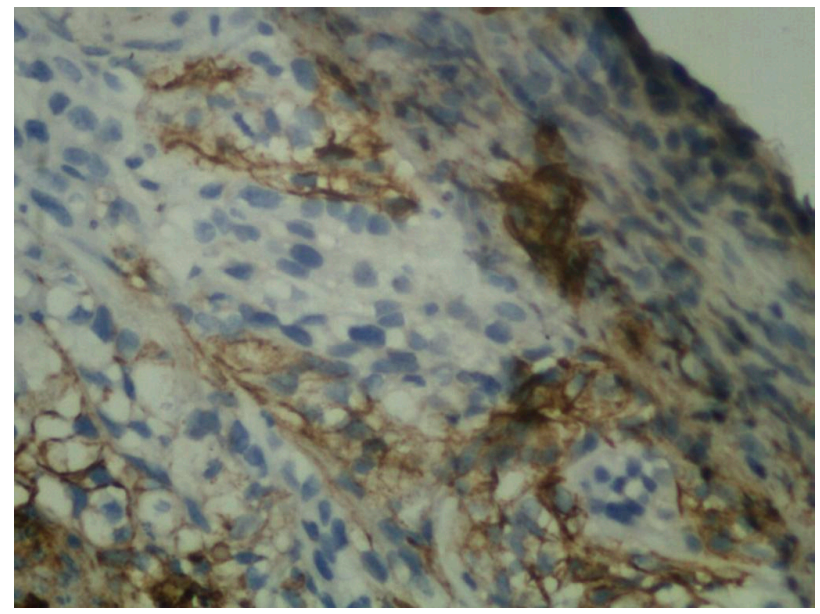

Control

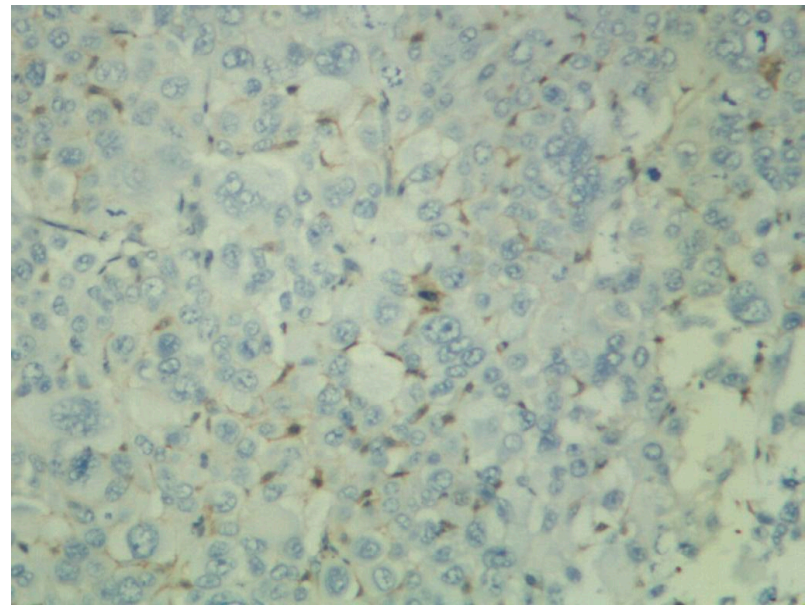

$\mathrm{SC}-560$ 


\subsection{Effect on Prostaglandin $E_{2}\left(P G E_{2}\right)$ Production}

To determine whether the anti-angiogenic activity of SC-560 in combination with cisplatin or taxol was due to the inhibition of $\mathrm{PG}$ synthesis, we tested prostaglandin $\mathrm{E}_{2}\left(\mathrm{PGE}_{2}\right)$ production by ELISA (Figure 4). The level of $\mathrm{PGE}_{2}$ in treatment groups was $25.75 \pm 1.49 \mathrm{ng} / \mathrm{mg}$ (SC-560), $37.51 \pm 1.76 \mathrm{ng} / \mathrm{mg}$ (cisplatin), $26.64 \pm 4.11 \mathrm{ng} / \mathrm{mg}$ (SC-560/cisplatin), $42.00 \pm 1.21 \mathrm{ng} / \mathrm{mg}$ (taxol) and $26.70 \pm 2.25 \mathrm{ng} / \mathrm{mg}$ (SC-560/taxol), which was statistically significant compared with that of the control group $(46.00 \pm 1.81 \mathrm{ng} / \mathrm{mg})\left(p<0.01\right.$ for all). In addition, SC-560 showed a greater reduction in $\mathrm{PGE}_{2}$ production than cisplatin and taxol $(p<0.01)$. SC-560 to influence prostaglandin synthesis suggests that effects of SC-560 are mostly due to inhibition of COX-1 activity.

Figure 4. SC-560 in combination with cisplatin or taxol affect prostaglandin $\mathrm{E}_{2}\left(\mathrm{PGE}_{2}\right)$ production. $\mathrm{PGE}_{2}$ of the control group compared with drug-treated groups illustrated the significant inhibitory effect of SC-560 in combination with cisplatin or taxol on tumor. ${ }^{*} \mathrm{PGE}_{2}$ of treatment groups compared with control group, $p<0.01$ for all; ${ }^{*} p<0.01$; error bars indicate standard error.

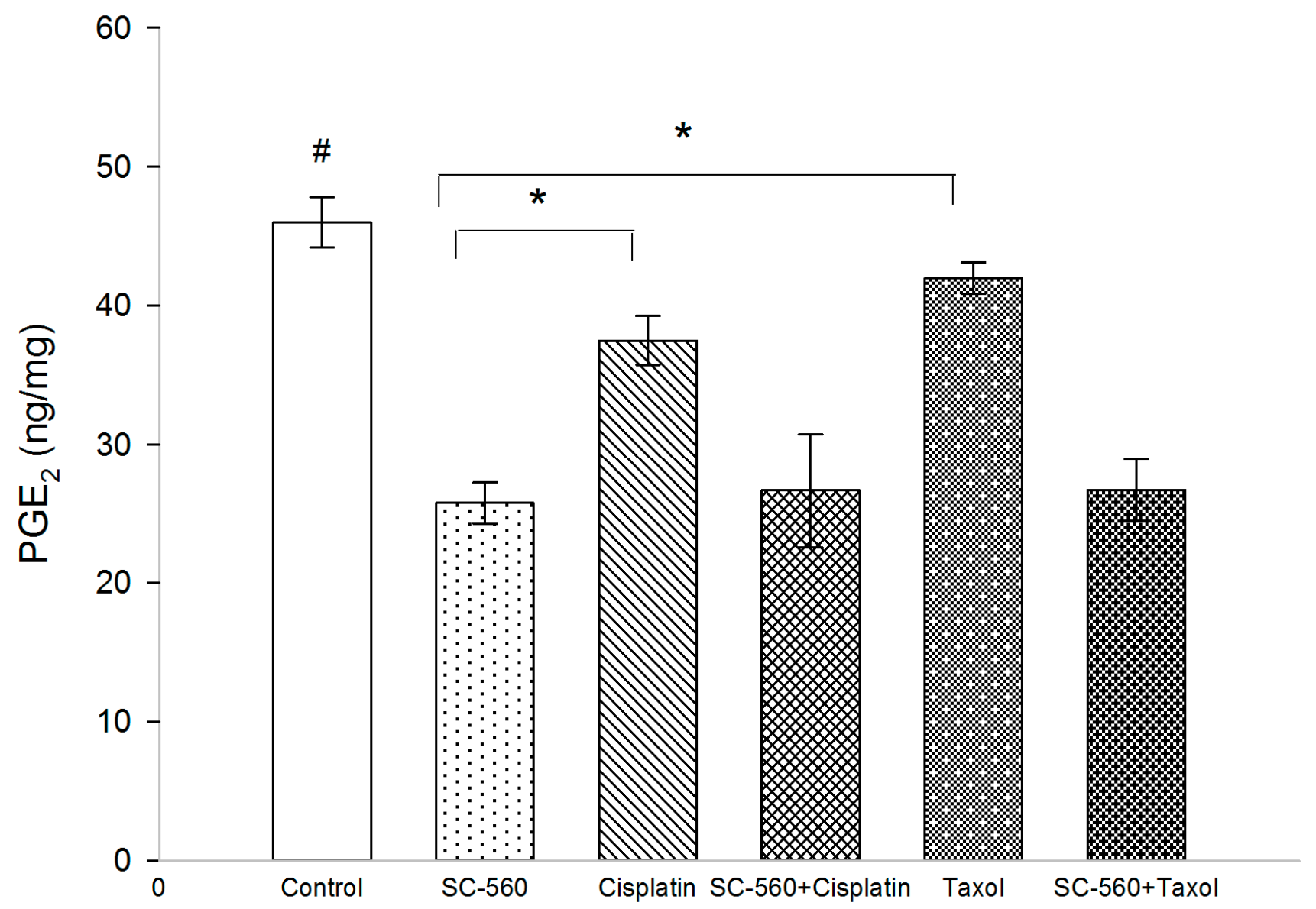

\subsection{Correlation of $P G E_{2}$ with $M V D$}

Linear equations were created to show the correlation between MVD and $\mathrm{PGE}_{2}$ (Figure 5). The analysis revealed a positive correlation between the expressions of $\mathrm{PGE}_{2}$ and MVD (correlation coefficient, $r=0.764, p<0.01)$. 
Figure 5. Correlation between the expressions of PGE2 and MVD $(r=0.764, p<0.01)$.

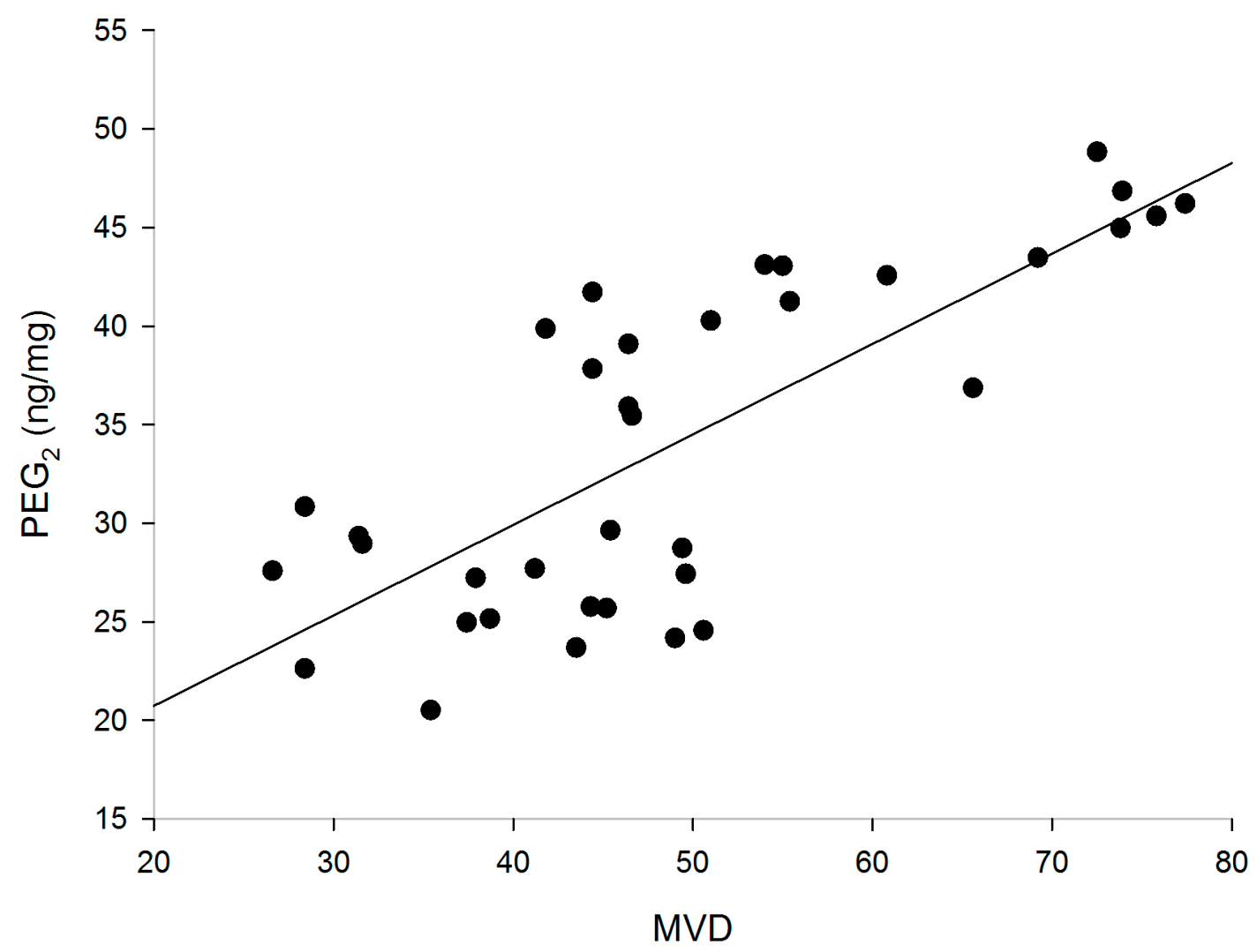

\subsection{Effect on Vascular Endothelial Growth Factor (VEGF) Production}

In this experiment, we measured VEGF levels in xenograft tumors by real-time PCR analysis. Three molecular isoforms of VEGF were generated by alternative splicing, rendering proteins containing 189-, 165- and 121-amino acid residues. Real-time PCR analysis indicated the $\Delta C_{\mathrm{t}}$ (cycle threshold, $\Delta C_{\mathrm{t}}=C_{\mathrm{t}, \text { selected gene }}-C_{\mathrm{t}, \beta \text {-actin}}$ ) of VEGF in the three groups (Table 1). As shown in Figure 6, the expression levels of VEGF mRNA were significantly suppressed in the treatment groups $(p<0.05$ for all). In addition, SC-560/cisplatin combination showed a greater inhibition on VEGF mRNA expression than SC-560 or cisplatin alone $(p<0.05)$. And SC-560/taxol combination therapy demonstrated a more synergistic effect than SC-560 or taxol alone on the inhibition of VEGF mRNA expression $(p<0.05)$.

Table 1. $\Delta C_{\mathrm{t}}$ of VEGF in the six groups (control, SC-560, cisplatin, SC-560/cisplatin combination group, taxol and SC-560/taxol combination group) ${ }^{\mathrm{a}}$.

\begin{tabular}{cccc}
\hline Group & VEGF 121 & VEGF 165 & VEGF 189 \\
\hline Control & $6.94 \pm 0.23$ & $4.58 \pm 0.26$ & $6.34 \pm 0.23$ \\
SC-560 & $7.13 \pm 0.30$ & $5.34 \pm 0.30$ & $6.54 \pm 0.21$ \\
Cisplatin & $7.71 \pm 0.38$ & $5.63 \pm 0.51$ & $7.14 \pm 0.28$ \\
SC-560 + Cisplatin & $8.16 \pm 0.36$ & $6.83 \pm 0.37$ & $8.27 \pm 0.42$ \\
Taxol & $7.87 \pm 0.32$ & $6.28 \pm 0.49$ & $7.79 \pm 0.29$ \\
SC-560 + Taxol & $9.14 \pm 0.33$ & $7.00 \pm 0.48$ & $8.99 \pm 0.23$ \\
\hline
\end{tabular}

${ }^{a}$ Molecular isoforms of VEGF were generated by alternative splicing, rendering proteins containing 189-, 165and 121-amino acid residues. VEGF 189, 165 and 121 were routinely detected in this series of ovarian cancer. 
Figure 6. Effects of the drugs on the expression of VEGF mRNA. \# VEGF mRNA expression levels of treatment groups compared with control group, $p<0.05$ for all; * $p<0.05$; error bars indicate standard error.

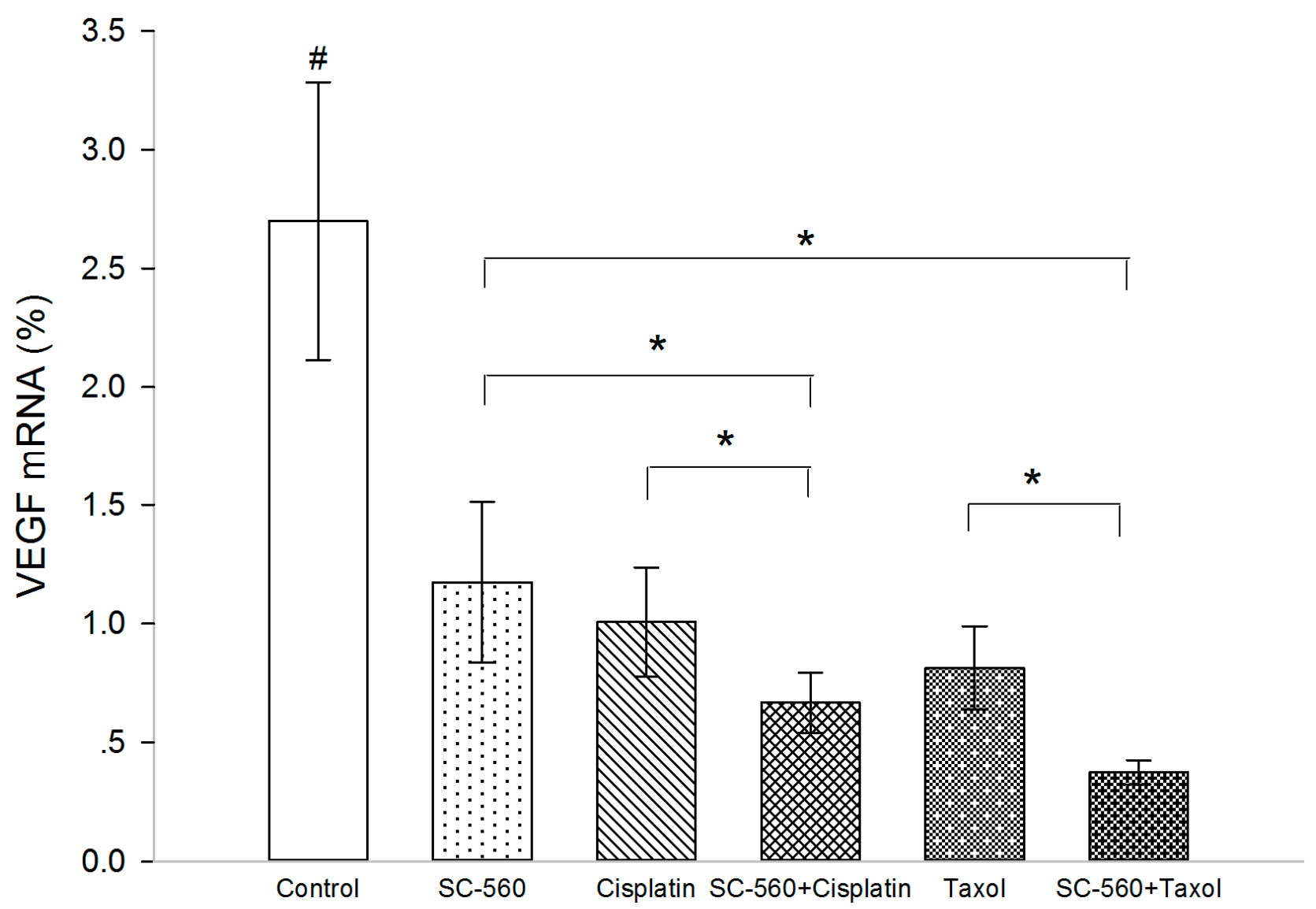

2.6. Cyclooxygenase-1 (COX-1) Expression

The untreated tumors were analyzed for expression COX-1 (Figure 7).

Figure 7. Immunohistochemical analysis of cyclooxygenase-1 (COX-1) expression in untreated tumor samples. Magnification is $100 \times$.

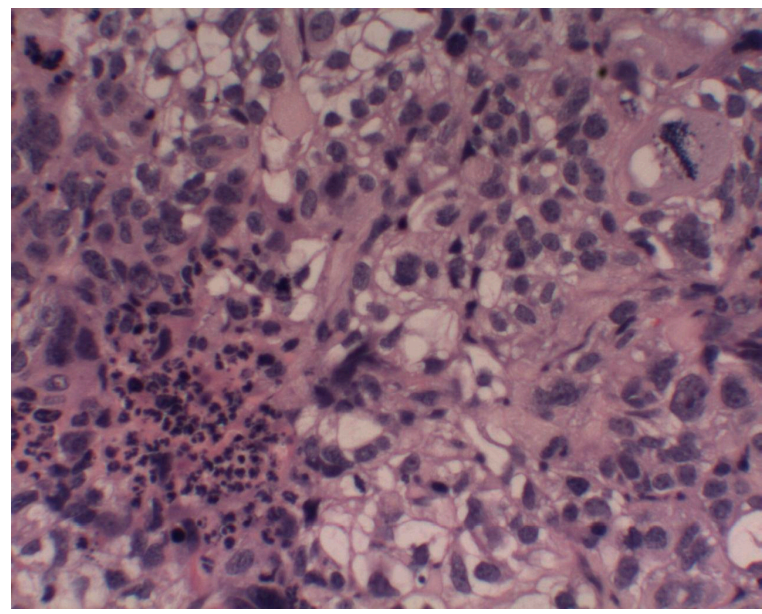

$\mathrm{H} \& \mathrm{E}$

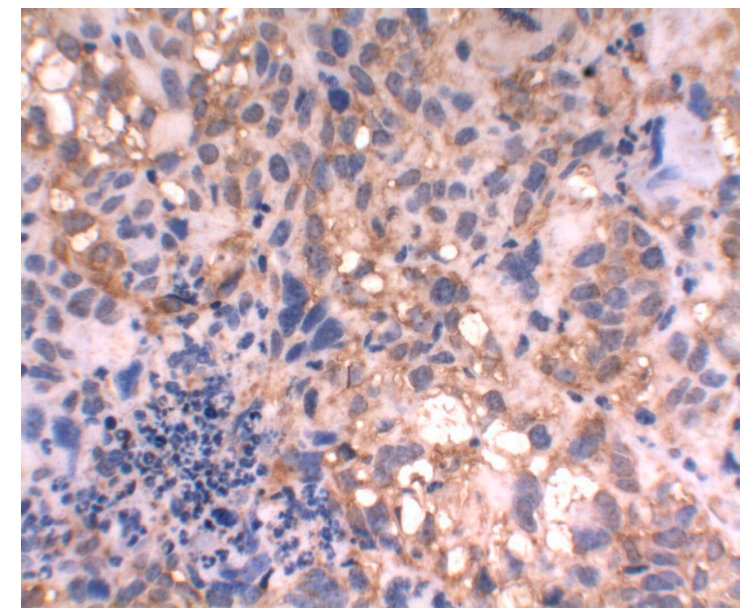

COX-1 


\subsection{Discussion}

The genetic and molecular mechanisms underlying ovarian cancer remain largely unknown, and treatment options for patients with advanced disease are limited [19]. In 1998, Dore M. et al. [14] used immunohistochemistry to demonstrate strong expression of COX-1, not COX-2, protein in human ovarian cancer specimens. Since then, concerted efforts have been focused on COX-1 up-regulation and $\mathrm{COX}$ inhibition in many malignant neoplasms. Epidemiological evidence suggests that COX inhibition may reduce the risk of epithelial ovarian cancer by $40 \%$ or more [28]. COX-1-selective inhibitor was demonstrated to suppress tumor growth and metastasis in mice with established epithelial ovarian cancer and COX-1 inhibition procedures are now being examined for the preclinical treatment of tumor $[13,17,19]$. Our previous studies have demonstrated that SC-560 has chemopreventive properties and SC-560 combined with taxol show stronger growth-inhibitory effect [27,29]. Recently, Vladimir et al. has demonstrated that SC-560 suppress vasodilation of coronary vessels in a canine model and their findings suggest that endothelial COX-1 may be the primary COX isoform in the normal coronary arteries that mediates arachidonic acid induced vasodilation [30,31].

Debulking surgery followed by platinum-taxane based chemotherapy is the standard of care for patients with advanced stage ovarian cancer; however, despite an encouraging response rate of $65 \%-80 \%$ to first-line chemotherapy, most patients relapse with chemoresistant disease which has been the main cause for the failure of chemotherapy [32]. The most important mechanism responsible for the multi-drug resistance (MDR) phenotype is the over-expression of drug efflux transporter genes in cancer cells [33]. Combination chemotherapy is one of the strategies being used to overcome drug resistance. A number of studies revealed that taxol up-regulates the COX-2 level in tumor cells and enhances MDR1 expression and functional activity [21,34]. Okada et al. was the first to report that a COX-2 inhibitor prevented cisplatin-induced tumorigenesis in a mouse model [35]. Therefore, the addition of COX-2 inhibitors to taxol is widely used for antitumor treatment and the combination therapy has been used in phase II trials of solid tumor treatment [24-26]. However, research on cisplatin or taxol in combination with COX-1-selective inhibitors used for the chemotherapy of ovarian cancer has rarely been conducted.

Angiogenesis refers to the recruitment of new blood vessels and forms an essential component of the metastatic pathway. Numerous studies have indicated that angiogenesis is considered essential for tumor growth and the development of metastases [36-38]. Ovarian cancer is known to be highly vascular and is a primary cancer in which current anti-angiogenic therapies are being tested [39]. The present study has shown that SC-560 combined with cisplatin or taxol significantly suppressed the ovarian cancer growth in mice by inhibiting the number of MVD and the production of VEGF, thus ultimately impeding tumor angiogenesis. Previous studies have found that the expression of COX-1 leads to an increased expression of VEGF and that the inhibition of COX-1 reverses this response $[17,27,40]$. The ability of the COX-1 inhibitor to limit tumor growth may be through an indirect effect on tumor angiogenesis. The increase of MVD, an indirect marker of intense tumor vascularization, is known to be associated with both evolution of disease and survival. In our experiment, MVD in treatment groups displayed a reduction compared with control group and a combination of SC-560 and cisplatin demonstrated a synergistic effect on MVD. Also, our results had shown the expression levels of VEGF mRNA in treatment groups was suppressed and SC-560 
combined with cisplatin or taxol therapy demonstrated synergistic effects. These results suggest that SC-560, when combined with cisplatin or taxol, enhances the anti-angiogenic effect of cisplatin or taxol. SC-560 may indirectly inhibit VEGF expression by inhibiting COX-1 expression and the decrease in tumor-associated VEGF may be a crucial mechanism in controlling angiogenesis. Recently, using the taxane-sensitive ovarian cancer cell line, SKOV-3, Lee et al. [41] reported that the combined treatment with paclitaxel and SC-560 promoted cytotoxicity in taxane-resistant ovarian cancers by suppressing MDRl gene and P-glycoprotein (P-gp), an ATP-binding cassette (ABC) transporter, expression. They reported that SC-560 significantly increased paclitaxel-induced cell death in taxane-resistant ovarian cancer cells in a prostaglandin- and COX-independent manner and their findings suggest that the COX-1 inhibitor can be a potent therapeutic tools not only as a drug sensitizer, but also as anti-angiogenic and pro-apoptotic agents. Their studies with taxane-sensitive ovarian cell lines were consistent with ours. Therefore, the potent anti-angiogenic activity of SC-560 combined with cisplatin or taxol seems to be the primary mechanism of action in the mice model of ovarian cancer.

In addition, the inhibition of COX-derived prostaglandin production was closely correlated with the decreased number of tumor MVD, and this result had been confirmed by Joarder et al. [42]. In our experiment, $\mathrm{PGE}_{2}$ levels were decreased in treatment groups compared with control mice and SC-560 showed a greater reduction in $\mathrm{PGE}_{2}$ production than cisplatin and taxol. The influence of SC-560 on $\mathrm{PGE}_{2}$ production suggests that effects of the COX-1 inhibitor are mostly due to inhibition of COX-1 expression; this result is in accordance with the study by Spinella et al. [43], who demonstrated that COX-1 inhibitor blocked $\mathrm{PGE}_{2}$ and VEGF release, indicating that COX-1 participates in $\mathrm{PGE}_{2}$ production. A previous study demonstrated that one of the mechanisms by which $\mathrm{PGE}_{2}$ supports tumor growth is by inducing the angiogenesis necessary to supply oxygen and nutrients to tumors $>2 \mathrm{~mm}$ in diameter [44]. COX-derived PGs contribute to tumor growth in mouse models by inducing newly formed blood vessels that sustain tumor cell viability and growth. Thus, inhibition of COX derived prostaglandin production was closely associated with inhibition of angiogenesis, which is essential for tumor growth and the development of metastases. The present study demonstrated that SC-560 inhibited the production of $\mathrm{PGE}_{2}$, and that $\mathrm{SC}-560$ enhanced the angiogenesis-inhibitory effect of cisplatin and taxol.

\section{Experimental Section}

\subsection{Human Ovarian Tumors in Nude Mice}

The human ovarian carcinoma cell lines SKOV3 in our experiments was chosen for its ability to mimic the progression of ovarian carcinoma when injected into in vivo mouse models and it could be well used to observe the antitumor effect $[45,46]$. The SKOV-3 cell line was purchased from China Type Culture Collection (Wuhan, China) and grown in the recommended media under standard condition. SKOV-3 cells were implanted subcutaneously in the dorsal skin $\left(2 \times 10^{6}\right.$ cells $)$ of female athymic nude mice (nu/nu, 7-8 weeks old). When the tumors became visible (7 days after inoculation), mice were randomly separated into six groups (six mice in each group): control, SC-560, cisplatin, SC-560/cisplatin, taxol and SC-560/taxol. 


\subsection{Dose and Administration of Drugs}

SC-560 (Sigma Chemical Co., St. Louis, MO, USA) was administered by oral gavage at a dose of $3 \mathrm{mg} / \mathrm{kg}$ twice a day. Taxol (Bristol Myers Squibb SRL, Sermoneta, Italy) was given by intraperitoneal (i.p.) at a dose of $20 \mathrm{mg} / \mathrm{kg}$ once a week. The drugs were suspended in a $0.5 \mathrm{~mL}$ suspension of $5 \%$ methylcellulose (Sigma Chemical Co.) and 0.025\% Tween 20 (Sigma Chemical Co.) Cisplatin was suspended in PBS ( $\mathrm{pH}$ 7.2) by i.p. injection at a dose of $3 \mathrm{mg} / \mathrm{kg}$ every other day. Cisplatin was purchased from Haoshen Pharmaceutical Co. (Jiangshu, China). The dose of SC-560 was chosen for their specificity in inhibiting COX isotypes [47]. In a control group, mice were treated with physiological saline under similar conditions. The drugs or vehicle were administered over a period of 21 days, commencing 7 days after the tumors became palpable.

\subsection{Measurement of Tumor Volume}

The tumor dimensions were measured twice a week using a linear caliper, and tumor volume was calculated using the equation $V\left(\mathrm{~mm}^{3}\right)=a \times b^{2} / 2$, where $a$ is the largest diameter and $b$ is the smallest diameter [48]. Tumor growth was evaluated by the inhibition rate as assessed by the formula: $I R=(C-T) / C \times 100 \%$, where $I R$ is the mean inhibition rate, $T$ is the mean tumor volume in the treatment group and $C$ is the mean tumor volume in the control group. The animals were weighed weekly throughout the experiment. On day 28, all of the mice were sacrificed, and tumor tissue samples were collected and then fixed in $10 \%$ phosphate-buffered formalin solution for immunohistology or stored at $80^{\circ} \mathrm{C}$ until analyzed. The tumor tissue samples were snap-frozen in liquid nitrogen before their storage at $-80^{\circ} \mathrm{C}$.

\subsection{Immunohistochemistry for MVD}

Formalin-fixed paraffin-embedded tumor sections $(6 \mu \mathrm{m})$ were subjected to immunostaining using CD34 antibodies (Santa Cruz Biotechnology, Dallas, TX, USA). Sections were deparaffinized and hydrated by sequential immersion in xylene and grade alcohol solutions. The sections were then incubated with $3 \%$ hydrogen peroxide in methanol solution for $34 \mathrm{~min}$ to block endogenous peroxidase activity. For antigen retrieval, slides were pressured in the pressure cooker for $2 \times 10 \mathrm{~min}$. For staining CD34, the sections were immersed in normal goat serum for $34 \mathrm{~min}$. Immunohistochemical staining was performed using the streptavidin-biotin method. Microvessel density (MVD) was evaluated according to the method first described by Weidrer et al. [49]. The entire tumor section was first carefully scanned at low magnification with light microscopy $(40 \times)$ to find the area that showed the most intense neovascularization. Because the immunohistochemistry of CD34 showed slight heterogeneity within the same tumor, the five most highly vascularized areas (hot spots) were selected in $200 \times$ magnification fields. The mean of five counts was calculated and used in statistical analysis.

\subsection{Real-Time PCR}

Total RNA was extracted using TRIzol reagents (Life Technologies, Shanghai, China), according to the manufacturer's instructions. Isolated RNA was electrophoresed through 1.0\% agarose-formaldehyde gels to verify the quality of the RNA. The first strand cDNA was generated by reverse transcription. 
After a sufficient amount of cDNA was obtained, we performed PCR amplification using a real-time PCR cycler (7500 ABI, ABI, New York, NY, USA). VEGF 189/165/121 RNAs were routinely detected in this series of ovarian cancer. The sequences of PCR primers were: VEGF (121), 5'-ACTCGG ATGCCGACACGGGA-3' and 5'-CCTGGCCTTGCTTGCTCCCC-3'; VEGF (165), 5'-CCAGGATCC TCTGCCCGCCT-3' and 5'-GCGGCTTCCGGCACCTACAG-3'; VEGF (189), 5'-GGCAAAAGTTGC GAGCCGCC-3' and 5'-TGGATGGACCGGGAGCAGGG-3'; $\beta$-actin, 5'-GGGTGACGAGGCCCA GAGCA-3' and 5'-GGGGCCACACGCAGCTCATT-3'.

Amplification system included $50 \mu \mathrm{L}$ of SYBRGreen Mix $(32.5 \mu \mathrm{L}), \mathrm{ddH}_{2} \mathrm{O}(14.5 \mu \mathrm{L})$, cDNA $(2 \mu \mathrm{L})$, forward primer $(0.5 \mu \mathrm{L})$ and reverse primer $(0.5 \mu \mathrm{L})$. The reaction conditions were as follows: Stage $1,50{ }^{\circ} \mathrm{C}$ for $2.00 \mathrm{~min}(1 \mathrm{cycle})$; Stage $2,95{ }^{\circ} \mathrm{C}$ for $5.00 \mathrm{~min}(1 \mathrm{cycle})$; Stage $3,95{ }^{\circ} \mathrm{C}$ for $0.25 \mathrm{~min}$ followed by $60{ }^{\circ} \mathrm{C}$ for $0.75 \mathrm{~min}$ (40 cycles); Stage $4,95{ }^{\circ} \mathrm{C}$ for $0.25 \mathrm{~min}$ firstly, then $60{ }^{\circ} \mathrm{C}$ for $1.00 \mathrm{~min}$, and lastly, $95^{\circ} \mathrm{C}$ for $0.25 \mathrm{~min}$ followed by $60{ }^{\circ} \mathrm{C}$ for $0.25 \mathrm{~min}$ ( 1 cycle).

The results of real-time PCR were analyzed by the DCT method: $\Delta C_{\mathrm{t}}=C_{\mathrm{t} \text {,selected gene }}-C_{\mathrm{t}, \beta \text {-actin }}, R Q$ (Relative Quantitation) $=2^{-\Delta C t} \times 100 \%$. The results of real-time PCR were presented as the ratio between the selected genes and $\beta$-actin transcripts.

\subsection{Determination of $P G E_{2}$ Levels in Tumor Tissues}

ELISAs: a PGE2 enzyme immunoassay kit (Cayman Chemical, Co., Ann Arbor, MI, USA) was used to quantify $\mathrm{PGE}_{2}$ concentrations in tumor extracts. $\mathrm{PGE}_{2}$ content in tumor tissue samples were determined using the method suggested by Trifan et al. [50]. Briefly, the tumor tissue samples were homogenized in prostaglandin extraction buffer $(0.1 \mathrm{M}$ phosphate, $\mathrm{pH} 7.4$, containing $1 \mathrm{mM}$ EDTA and $10 \mu \mathrm{M}$ indomethacin) and incubated on wet ice for $30 \mathrm{~min}$. The samples were centrifuged, and the supernatant was collected. A known volume of supernatant (typically $500 \mu \mathrm{L}$ ) was dried under nitrogen and resuspended in assay buffer and was analyzed as per the manufacturer's recommendations (Cayman Chemical Co.). $\mathrm{PGE}_{2}$ values were expressed as microgram per milligram protein in the tissue samples.

\subsection{Statistical Analysis}

Statistical analysis was performed using SPSS software (SPSS version 17.0; SPSS, Chicago, IL, USA). Statistical significance between the control and treated groups was determined using the Student's $t$-test. The experimental data were shown as the means \pm standard error (SE). $p<0.05$ was considered to indicate a statistically significant result.

\section{Conclusions}

Our data imply that cisplatin or taxol supplemented by SC-560 in the treatment of human ovarian cancer xenografts provides a synergistic inhibition effect compared to cisplatin or taxol alone on angiogenesis. However, whether COX-1 inhibitors combined with cisplatin or taxol therapy can be adopted as a new chemotherapy regimen in the treatment of ovarian cancer requires further intense research efforts. 


\section{Acknowledgments}

We thank Professor Rujun Xu (Department of Pathology, First People's hospital of Hangzhou, Hangzhou, China) for her help in pathology test.

\section{Author Contributions}

Wei Li: Corresponding author, reviewed and modified the paper; Liang Wan: Implemented the experiments and wrote the article; and Ling-Yun Zhai and Jane Wang: Data calculations and data analysis using the Statistical Package for Social Sciences (SPSS version 19.0) software.

\section{Conflicts of Interest}

The authors declare no conflict of interest.

\section{References}

1. Woopen, H.; Sehouli, J. Current and future options in the treatment of malignant ascites in ovarian cancer. Anticancer Res. 2009, 29, 3353-3359.

2. Li, L.; Wang, L.M.; Zhang, W.; Tang, B.J.; Zhang, J.Q.; Song, H.L.; Yao, D.S.; Tang, Y.; Chen, X.Q.; Yang, Z.H.; et al. Correlation of serum VEGF levels with clinical stage, therapy efficacy, tumor metastasis and patient survival in ovarian cancer. Anticancer Res. 2004, 24, 1973-1980.

3. Wu, H.; Wang, K.; Liu, W.; Hao, Q. PTEN over-expression improves cisplatin-resistance of human ovarian cancer cells through up-regulating KRT10 expression. Biochem. Biophys. Res. Commun. 2014, 444, 141-146.

4. Stordal, B.; Pavlakis, N.; Davey, R. A systematic review of platinum and taxane resistance from bench to clinic: An inverse relationship. Cancer Treat. Rev. 2007, 33, 688-703.

5. Go, R.S.; Adjei, A.A. Review of the comparative pharmacology and clinical activity of cisplatin and carboplatin. J. Clin. Oncol. 1999, 17, 409-422.

6. Boeckman, H.J.; Trego, K.S.; Turchi, J.J. Cisplatin sensitizes cancer cells to ionizing radiation via inhibition of nonhomologous end joining. Mol. Cancer Res. 2005, 3, 277-285.

7. Kelland, L. The resurgence of platinum-based cancer chemotherapy. Nat. Rev. Cancer 2007, 7, 573-584.

8. Lawson, E.; Irada, I.; Hamdi, J.; Sevtap, S.; Mehran, M.; Kathleen, I.P.; Hilmi, O. Bioinformatic analyses identifies novel proteincoding pharmacogenomic markers associated with paclitaxel sensitivity in NCI60 cancer cell lines. BMC Med. Genomics 2011, 4, 18.

9. Kohler, D.R.; Goldspiel, B.R. Evaluation of new drugs: Paclitaxel (taxol). Pharmacotherapy 1994, 14, 3-34.

10. Wang, Y.; Qu, Y.; Niu, X.L.; Sun, W.J.; Zhang, X.L.; Li, L.Z. Autocrine production of interleukin-8 confers cisplatin and paclitaxel resistance in ovarian cancer cells. Cytokine 2011, 56, 365-375.

11. Blobaum, A.L.; Marnett, L.J. Structural and functional basis of cyclooxygenase inhibition. J. Med. Chem. 2007, 50, 1425-1441. 
12. Radi, Z.A.; Khan, N.K. Effect of cyclooxygenase inhibition on the gastrointestinal tract. Exp. Toxicol. Pathol. 2006, 58, 163-173.

13. Daikoku, T.; Wang, D.Z.; Tranguch, S.; Morrow, J.D.; Orsulic, S.; Dubois, R.N.; Dey, S.K. Cyclooxygenase-1 is a potential target for prevention and treatment of ovarian epithelial cancer. Cancer Res. 2005, 65, 3735-3744.

14. Dore, M.; Cote, L.C.; Mitchell, A.; Sirois, J. Expression of prostaglandin G/H synthase type 1, but not type 2, in human ovarian adenocarcinomas. J. Histochem. Cytochem. 1998, 46, 77-84.

15. Sales, K.J.; Katz, A.A; Howard, B.; Soeters, R.P.; Millar, R.P.; Jabbour, H.N. Cyclooxygenase-1 is up-regulated in cervical carcinomas: autocrine/paracrine regulation of cyclooxygenase-2, prostaglandine receptors, and angiogenic factors by cyclooxygenase-1. Cancer Res. 2002, 62, 424-432.

16. Erovic, B.M.; Woegerbauer, M.; Pammer, J.; Selzer, E.; Grasl, M.Ch.; Thurnher, D. Strong evidence for up-regulation of cyclooxygenase-1 in head and neck cancer. Eur. J. Clin. Investig. 2008, 38, 61-66.

17. Gupta, R.A.; Tejada, L.V.; Tong, B.J.; Das, S.K.; Morrow, J.D.; Dey, S.K.; Dubois, R.N. Cyclooxygenase-1 is over-expressed and promotes angiogenic growth factor production in ovarian cancer. Cancer Res. 2003, 63, 906-911.

18. Urick, M.E.; Johnson, P.A. Cyclooxygenase 1 and 2 mRNA and protein expression in the Gallus domesticus model of ovarian cancer. Gynecol. Oncol. 2006, 103, 673-678.

19. Daikoku, T.; Tranguch, S.; Trofimova, I.N.; Dinulescu, D.M.; Jacks, T.; Nikitin, A.Y.; Connolly, D.C.; Dey, S.K. Cyclooxygenase-1 is over-expressed in multiple genetically engineered mouse models of epithelial ovarian cancer. Cancer Res. 2006, 66, 2527-2531.

20. Ferrandina, G.; Lauriola, L.; Zannoni, G.F.; Faqotti, A.; Fanfani, F.; Maqqiano, N.; Gessi, M.; Mancuso, S.; Ranelletti, F.O; Scambia, G. Increased cyclooxygenase-2 (COX-2) expression is associated with chemotherapy resistance and outcome in ovarian cancer patients. Ann. Oncol. 2002, 13, 1205-1211.

21. Subbaramaiah, K.; Hart, J.C.; Norton, L.; Dannenberq, A.J. Microtubule-interfering agents stimulate the transcription of cyclooxygenase-2: Evidence for involvement of ERK1/2 and p38 mitogen-activated protein kinase pathways. J. Biol. Chem. 2000, 275, 14838-14845.

22. Munkarah, A.R.; Ali-Fehmi, R.; Jiang, J.Z.; Elhammady, E.; Malone, J.M., Jr.; Saed, G.M. The effects of combining docetaxel and cyclooxygenase- 2 inhibitors on proliferation and apoptosis in epithelial ovarian cancer. Anticancer Drugs 2007, 18, 889-896.

23. Bijman, M.N.; Hermelink, C.A.; van Berkel, M.P.; Laan, A.C.; Janmaat, M.L.; Peters, G.J.; Boven, E. Interaction between celecoxib and docetaxel or cisplatin in human cell lines of ovarian cancer and colon cancer is independent of COX-2 expression levels. Biochem. Pharmacol. 2008, $75,427-437$.

24. Mutter, R.; Lu, B.; Carbone, D.P.; Csiki, I.; Moretti, L.; Johnson, D.H.; Morrow, J.D.; Sandler, A.B.; Shyr, Y.; Ye, F.; et al. A phase II study of celecoxib in combination with paclitaxel, carboplatin, and radiotherapy for patients with inoperable stage IIIA/B non-small cell lung cancer. Clin. Cancer Res. 2009, 15, 2158-2165. 
25. Bhatt, R.S.; Merchan, J.; Parker, R.; Wu, H.K.; Zhang, L.; Seery, V.; Heymach, J.V.; Atkins, M.B.; Mcdermott, D.; Sukhatme, V.P. A phase 2 pilot trial of low-dose, continuous infusion, or "metronomic" paclitaxel and oral celecoxib in patients with metastatic melanoma. Cancer 2010, 116, 1751-1756.

26. Altorki, N.K.; Christos, P.; Port, J.L.; Lee, P.C.; Mirza, F.; Spinelli, C.; Keresztes, R.; Beneck, D.; Paul, S.; Stiles, B.M.; et al. Preoperative taxanebased chemotherapy and celecoxib for carcinoma of the esophagus and gastroesophageal junction: Results of a phase 2 trial. J. Thorac. Oncol. 2011, 6, 1121-1127.

27. Li, W.; Xu, R.J.; Lin, Z.Y.; Zhuo, G.C.; Zhang, H.H. Effects of a cyclooxygenase-1-selective inhibitor in a mouse model of ovarian cancer, administered alone or in combination with ibuprofen, a nonselective cyclooxygenase inhibitor. Med. Oncol. 2009, 26, 170-177.

28. Moysich, K.B.; Mettlin, C.; Piver, M.S.; Natarajan, N.; Menezes, R.J.; Swede, H. Regular use of analgesic drugs and ovarian cancer risk. Cancer Epidemiol. Biomark. Prev. 2001, 10, 903-906.

29. Li, W.; Cai, J.H.; Zhang, J.; Tang, Y.X.; Wan, L. Effects of cyclooxygenase inhibitors in combination with taxol on expression of cyclin d1 and ki-67 in a xenograft model of ovarian carcinoma. Int. J. Mol. Sci. 2012, 13, 9741-9753.

30. Zivkovic, V.; Djuric, D.; Turjacanin-Pantelic, D.; Marinkovic, Z.; Stefanovic, D.; Srejovic, I.; Jakovljevic, V. The effects of cyclooxygenase and nitric oxide synthase inhibition on cardiodynamic parameters and coronary flow in isolated rat hearts. Exp. Clin. Cardiol. 2013, 18, e102-e110.

31. Hong, T.T.; Huang, J.; Barrett, T.D.; Lucchesi, B.R. Effects of cyclooxygenase inhibition on canine coronary artery blood flow and thrombosis. Am. J. Physiol. Heart Circ. Physiol. 2008, 294, H145-H155.

32. Gamarra-Luques, C.D.; Hapon, M.B.; Goyeneche, A.A.; Telleria, C.M. Resistance to cisplatin and paclitaxel does not affect the sensitivity of human ovarian cancer cells to antiprogestin-induced cytotoxicity. J. Ovarian Res. 2014, 7, 45.

33. Szakacs, G.; Paterson, J.K.; Ludwig, J.A.; Booth-Genthe, C.; Gottesman, M.M. Targeting multidrug resistance in cancer. Nat. Rev. Drug Discov. 2006, 5, 219-234.

34. Ratnasinghe, D.; Daschner, P.J.; Anver, M.R.; Kasprzak, B.H.; Taylor, P.R.; Yeh, G.C.; Tangrea, J.A. Cyclooxygenase-2, P-glycoprotein-170 and drug resistance; is chemoprevention against multidrug resistance possible? Anticancer Res. 2001, 21, 2141-2147.

35. Okada, T.; Takigawa, N.; Kishino, D.; Katayama, H.; Kuyama, S.; Sato, K.; Mimoto, J.; Ueoka, H.; Tanimoto, M.; Kiura, K. Selective cyclooxygenase-2 inhibitor prevents cisplatin-induced tumorigenesis in A/J mice. Acta. Med. Okayama 2012, 66, 245-251.

36. Harlozinska, A.; Sedlaczek, P.; Kulpa, J.; Grybos, M.; Wójcik, E.; van Dalen, A.; Einarsson, R. Vascular endothelial growth factor (VEGF) concentration in sera and tumor effusions from patients with ovarian carcinoma. Anticancer Res. 2004, 24, 1149-1157.

37. Prager, G.W.; Poettler, M. Angiogenesis in cancer. Basic mechanisms and therapeutic advances. Hamostaseologie 2011, 32, 105-114.

38. Hicklin, D.J.; Ellis, L.M. Role of the vascular endothelial growth factor pathway in tumor growth and angiogenesis. J. Clin. Oncol. 2005, 23, 1011-1027. 
39. Hazelton, D.A.; Hamilton, T.C. Vascular endothelial growth factor on ovarian cancer. Curr. Oncol. Rep. 1999, 1, 59-63.

40. Von Rahden, B.H.; Stein, H.J.; Pühringer, F.; Koch, I.; Langer, R.; Piontek, G.; Siewert, J.R.; Höler, H.; Sarbia, M. Coexpression of cyclooxygenases (COX-1, COX-2) and vascular endothelial growth factors (VEGF-A, VEGF-C) in esophageal adenocarcinoma. Cancer Res. 2005, 65, 5038-5044.

41. Lee, J.P.; Hahn, H.S.; Hwang, S.J.; Choi, J.Y.; Park, J.S.; Lee, I.H.; Kim, T.J. Selective cyclooxygenase inhibitors increase paclitaxel sensitivity in taxane-resistant ovarian cancer by suppressing P-glycoprotein expression. J. Gynecol. Oncol. 2013, 24, 273-279.

42. Joarder, F.; Abouissa, H.; Robertson, F.; Parrett, M.; Alshafie, G.; Harris, R. Growth arrest of DMBA-induced mammary carcinogenesis with ibuprofen treatment in female Sprague-Dawley rats. Oncol. Rep. 1997, 4, 1271-1273.

43. Spinella, F.; Rosano, L.; di Castro V.; Nicotra, M.R.; Natali, P.G.; Bagnato, A. Inhibition of cyclooxygenase-1 and -2 expression by targeting the endothelin a receptor in human ovarian carcinoma cells. Clin. Cancer Res. 2004, 10, 4670-4679.

44. Hanahan, D.; Folkman, J. Patterns and emerging mechanisms of the angiogenic seich during tumorigenesis. Cell 1996, 86, 353-364.

45. Munkarah, A.R.; Genhai, Z.; Morris, R.; Baker, W.; Ceppe, G.; Diamond, M.P.; Saed, G.M. Inhibition of paclitaxel-induced apoptosis by the specific COX-2 inhibitor, NS398, in epithelial ovarian cancer cells. Gynecol. Oncol. 2003, 88, 429-433.

46. Devalapally, H.; Duan, Z.F.; Seiden, M.V.; Amiji, M.M. Modulation of drug resistance in ovarian adenocarcinoma by enhangcing intracellular ceramide using tamoxifen-loaded bioderadable polymeric nanoparticles. Clin. Cancer Res. 2008, 14, 3193-3203.

47. Reese, J.; Zhao, X.; Ma, W.G.; Brown, N.; Maziasz, T.J.; Dey, S.K. Comparative analysis of pharmacologic and/or genetic disruption of cyclooxygenase-1 and cyclooxygenase-2 function in female reproduction in mice. Endocrinology 2001, 142, 3198-3206.

48. Williams, C.S.; Watson, A.J.M.; Sheng, H.; Helou, R.; Shao, J.; DuBois, R.N. Celecoxib prevents tumor growth in vivo without toxicity to normal gut: lack of correlation between in vitro and in vivo models. Cancer Res. 2000, 60, 6045-6051.

49. Weidner, N.; Folkman, J.; Pozza, F.; Bevilacqua, P.; Allred, E.N.; Moore, D.H.; Meli, S.; Gasparini, G. Tumor angiogenesis: A new significant and independent prognostic indicator in early-stage breast carcinoma. J. Natl. Cancer Inst. 1992, 84, 1875-1887.

50. Trifan, O.C.; Durham, W.F.; Salazar, V.S.; Horton, J.; Levine, B.D.; Zweifel, B.S.; Davis, T.W.; Masferer, J.L. Cyclooxygenase-2 inhibition with celecoxib enhances antitumor efficacy and reduces diarrhea side effect of CPT-11. Cancer Res. 2002, 62, 5778-5784.

(C) 2014 by the authors; licensee MDPI, Basel, Switzerland. This article is an open access article distributed under the terms and conditions of the Creative Commons Attribution license (http://creativecommons.org/licenses/by/4.0/). 